Paper published in Transportation Geotechnics 18 (1029) 142-148

https://doi.org/10.1016/j.trgeo.2018.12.004

\title{
Investigation into the critical speed of ballastless track
}

\author{
Jing $\mathrm{Hu}^{\mathrm{a}}$, Xuecheng Bian ${ }^{\mathrm{a}}$, Weichang $\mathrm{Xu}^{\mathrm{b}}$, David Thompson ${ }^{\mathrm{c}}$
}

${ }^{\mathrm{a}}$ Department of Civil Engineering, Zhejiang University, Hangzhou, China, 310058

${ }^{\mathrm{b}}$ China Railway Shanghai Group Co., Ltd

${ }^{\mathrm{c}}$ Institute of Sound and Vibration Research, University of Southampton, University Road, Highfield, Southampton SO17 1BJ, UK

\section{"Corresponding Author :}

Xuecheng Bian

Department of Civil Engineering, Zhejiang University,

Hangzhou, China, 310058

E-mail: bianxc@zju.edu.cn 


\begin{abstract}
As train speeds are increased, the issue of the critical speed must be faced, especially when tracks run across soft ground. This is the phenomenon describes the amplification of the track deflections due to coincidence of the train speed with the wavespeeds of the underlying ground. Modern high-speed lines are often constructed on ballastless track which has different dynamic behaviour to conventional ballasted track. Therefore, further research is needed to investigate the critical speed of ballastless track. In this paper, a dynamic analysis model comprising track, embankment and ground is presented based on the two-and-half-dimensional (2.5D) finite element method to predict the vibrations generated by train moving loads. The rails and track slab are modeled as Euler-Bernoulli beams resting on the embankment. The concrete base, embankment and ground are modeled by the $2.5 \mathrm{D}$ finite elements. The results show that the critical speed of ballastless track is higher than the Rayleigh wave velocity of the underlying soil and quite close to the Rayleigh wave velocity of the subgrade. The existence of the subgrade can highly improve the critical speed of the ballastless track even with a shallow subgrade of $1.25 \mathrm{~m}$ depth. The underlying soil stiffness is the conclusive factor in determining the track vibration amplitude. It is also found that the embankment plays an essential role in reducing the inhomogeneity of the lateral stress distribution and the amplitude of vertical stress in ballastless track.
\end{abstract}

Keywords: 2.5D finite element method; High-speed train; Critical speed; Ballastless track; Dynamic stress 


\section{Introduction}

In recent decades, high-speed railways have developed rapidly all over the world. For instance, the Shinkansen network in Japan now has a length of $4072 \mathrm{~km}$. On the other hand, China has built the world's largest high-speed rail network which now exceeds $22,000 \mathrm{~km}$, with common operating speed train speeds up to $350 \mathrm{~km} / \mathrm{h}$. The Chinese railway administration expects to increase high speed traffic up to $400 \mathrm{~km} / \mathrm{h}$ in the near future. As the train speed increases, dynamic responses of the railway track and ground along the railway line become more substantial, primarily due to the significant amplification effect of the track-ground vibration [1, 2].

The train-induced vibration of the track and ground is strongly affected by the relationship between the train speed and the corresponding propagating wave velocity of the supporting media. The speed at which large amplification of the dynamic response occurs is named the 'critical speed'. At the critical speed, train moving loads induce strong vibration in the track structure, and increase the risk of train derailment and track structure damage. This phenomenon has been measured as a manifestation of the existence of the critical speed in the experience of the Swedish Rail Administration (SRA). In 1997, SRA started running the X-2000 passenger high-speed train (HST) along the West Coast Line between Göteborg and Malmö. Excessive vibrations in the railway embankment and the surrounding soil were observed at the Ledsgård site (where the railway track was laid on soft soil). Inspection of the track revealed that the maximum amplitude of track vibration reached $15 \mathrm{~mm}-20 \mathrm{~mm}$ and the vehicle and track generated significant vibrational resonance as the speed of the train was increased to $200 \mathrm{~km} / \mathrm{h}$. The train speed was immediately reduced by the SRA as a consequence. This incident revealed problems ensuing from the critical speed. Due to the practical significance of this matter, several efforts $[3,4]$ were made to understand the track responses and determine the optimum running speed of the X-2000 HST at the Ledsgård site using different empirical methods. Remediation was introduced at the site in the form of lime-cement columns to stabilize the ground[5]. Subsequent to this case study, several analytical and numerical approaches have been proposed by a number of researchers to assess the critical speed and associated issues [6-14].

However, most existing track-ground models are based on the simplification of the track structure and embankment as a beam resting on a homogeneous ground; no closed-formed solutions can be readily obtained for realistic railway geometry and materials used in 
embankments and grounds. In fact, embankments, which usually contain roadbed and subgrade, are commonly constructed on soft soil grounds to keep trains safe and compensate for long-term settlement under a repeated moving train load. Due to the complex properties of the track, embankment and ground, the determining the critical speed of train operations remains difficult. A dynamic analysis model comprising embankment and layered ground was presented by Bian et al. [15] using a 2.5D finite element method combined with the thin-layer element method. It revealed that the critical speed of a train moving on an embankment is higher than the Rayleigh wave velocity of the underlying soil, attributed to the presence of the embankment. Recently, Sayeed and Shahin [13] built a three-dimensional (3D) finite element (FE) ballasted railway track model of the X-2000 HST to simulate the dynamic response of railway track foundations under true train moving loads, with special reference to the critical speed.

Ballastless tracks are commonly adopted for high-speed lines; in China most of the high-speed network is constructed with ballastless track. This adopts rigid concrete structures to replace the traditional ballast layer used for ballasted tracks. Because of the different track structures and much higher train speeds, ballastless railways have dynamic performances that are quite different from those of ballasted railways, such as transient responses and permanent deformation. It can be expected that the critical speed will also be affected by the track structure. Thus, further research is needed to investigate the critical speed of ballastless track.

In this paper, a $2.5 \mathrm{D}$ finite element model of ballastless track is presented to predict the critical speed and study ground vibrations induced by trains moving at various speeds, accounting for the dynamic track-embankment-ground interaction. In the following sections, first, the $2.5 \mathrm{D}$ finite element method is briefly introduced, and then a ballastless track model is built and verified with the test results of the full-scale physical model built in Zhejiang University $[16,17]$. A parametric study is performed based on this model to determine the critical speed of train operation. The dynamic response of the ballastless track structure under a series of train speeds and the consequent wave propagation in ground are discussed.

\section{Numerical modelling}

\subsection{FEM modelling of railway track foundation system}

In this section, an investigation is presented of the dynamic response of ballastless track subjected to train moving loads via 2.5D FEM modelling using the commercial software Matlab. It is 
important to ensure that the FE modelling process was capable of providing reliable outcomes. To this end, an initial analysis on the physical model that is well documented in the literature [17] is performed to ascertain that the model could reproduce model test results of compiled measurements.

\section{Brief introduction of $2.5 D$ finite element method}

For ballastless track, the material and geometry of the structure and supporting ground can be treated as approximately constant in the longitudinal direction. Therefore, the wave propagation in this direction can be represented by the superposition of harmonic waves with a certain wavenumber. This method using the $2 \mathrm{D}$ profile to compute the $3 \mathrm{D}$ wave propagation under dynamic loading, is referred to as the $2.5 \mathrm{D}$ method, and has been applied to evaluate the dynamic response of solid structures due to traffic moving loads [18-21]. For ballastless track, the rails and track slab are each modeled as a single Euler beam with mass per unit length of track $m_{r}$ and $m_{s}$, and bending stiffness $E I_{\mathrm{r}}$ and $E I_{\mathrm{s}}$. The concrete base, embankment and ground in the transverse-vertical section are discretized and modeled by 4-node quadrilateral elements for specific discrete wavenumbers. Each node of the element has three degrees of freedom allowing wave propagation in three-dimensional space to be taken into account faithfully. This approach greatly reduces the computational time compared with conventional numerical models while maintaining computational accuracy of the wave propagation in three-dimensional space[21]. In the current work the ground is assumed to behave as a linear elastic solid.

A Fourier transform is performed with respect to the time $t$ and the train running direction $x$, (where subscripts $x$ and $t$ represent components in the wavenumber and frequency domain respectively),

$u^{x t}=\int_{-\infty}^{+\infty} \int_{-\infty}^{+\infty} u(x, t) \exp \left(i \xi_{x} x\right) \exp (-i \omega t) d \xi_{x} d t$

and the corresponding inverse transform is,

$$
u=\int_{-\infty}^{+\infty} \int_{-\infty}^{+\infty} u^{x t}(x, t) \exp \left(i \xi_{x} x\right) \exp (-i \omega t) d \xi_{x} d t
$$

where $\xi_{x}$ is the wavenumber in the $x$-direction, $\omega$ is the circular frequency. The finite element model of the track-ground system is shown in Fig. 1. In this paper, it is assumed that the vertical displacement between the track and the ground is continuous, and the ground materials making up the embankment and track structure are elastic, with the distributed sleepers embedded in the continuous track slab. 


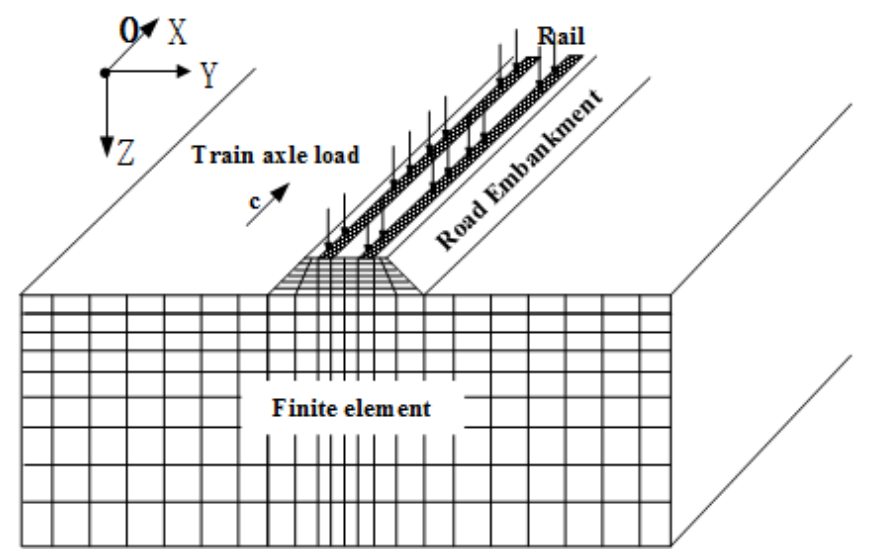

Fig. 1. Finite element-thin layer element model of track-ground system

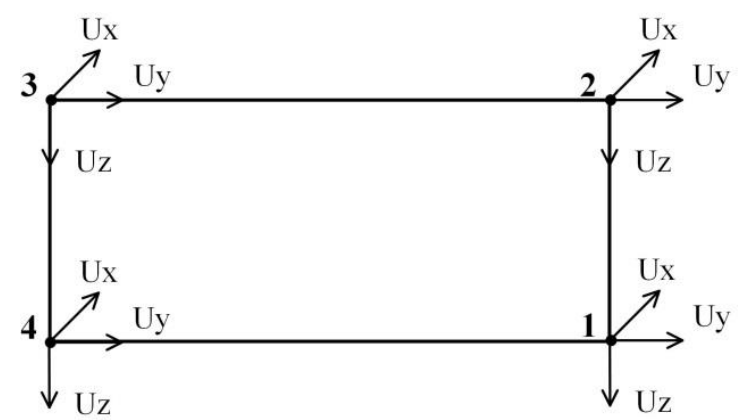

Fig. 2. 2.5D finite element nodes

A typical 2.5D quadrilateral finite element is shown in Fig. 2; each node has three translational degrees of freedom. After introducing the shape function, the discretized form of the governing equation in the frequency domain can be derived by the conventional finite element method:

$$
\left(\mathbf{K}^{x t}-\omega^{2} \mathbf{M}\right) \mathbf{U}^{x t}=\mathbf{F}^{x t}
$$

where $\mathbf{M}, \mathbf{K}^{x t}$ and $\mathbf{F}^{x t}$ are the mass matrix, stiffness matrix and equivalent nodal force vectors, respectively, and their detailed expressions are

$$
\begin{aligned}
& \mathbf{M}=\sum_{e} \rho^{e} \iint \mathbf{N}^{T} \mathbf{N}|\mathbf{J}| d \eta d \zeta \\
& \mathbf{K}^{x t}=\sum_{e} \iint\left(\mathbf{B}^{*} \mathbf{N}\right)^{T} \mathbf{D}(\mathbf{B N})|\mathbf{J}| d \eta d \zeta \\
& \mathbf{F}^{x t}=\sum_{e} \iint \mathbf{N}^{T} \mathbf{f}|\mathbf{J}| d \eta d \zeta
\end{aligned}
$$

where $\mathbf{J}$ is the Jacobi matrix, $\mathbf{N}$ is the shape function matrix, $\mathbf{B}$ is strain matrix, $\mathbf{D}$ is elastic matrix, $\mathbf{f}$ is applied load, $\eta$ and $\zeta$ are the local coordinates of the element. The detailed expressions for $\mathbf{J}, \mathbf{B}$ and $\mathbf{D}$ are given in [18]. 


\section{Full-scale physical model of a ballastless high-speed railway track}

A full-scale physical model of a ballastless high-speed railway track was established according to the practical engineering design methods in Zhejiang University [17]. The physical model of a slab track-embankment system comprises, from the bottom to the top, a $2.5 \mathrm{~m}$-deep ground, a $2.3 \mathrm{~m}$-thick subgrade, a $0.4 \mathrm{~m}$-thick roadbed, a $0.3 \mathrm{~m}$-thick concrete base, a $0.05 \mathrm{~m}$ layer of cement asphalt mortar (CAM), a 0.19 m-thick track slab, fasteners, and rails, as shown in Fig. 3.

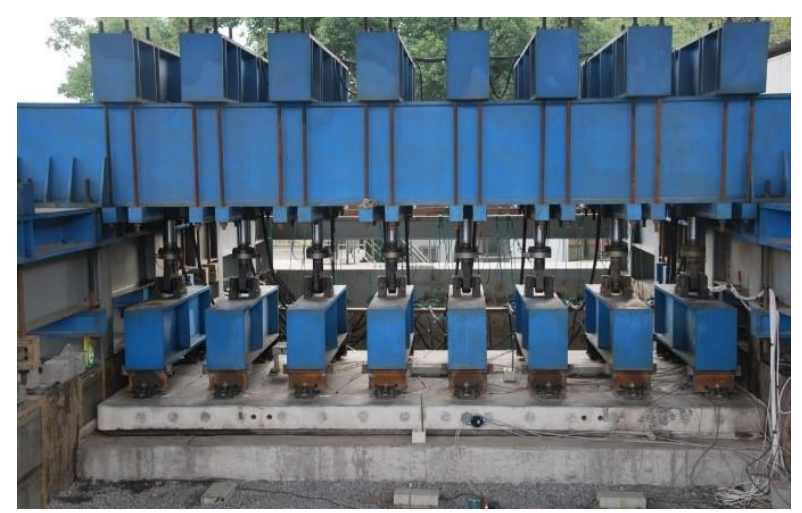

(a)

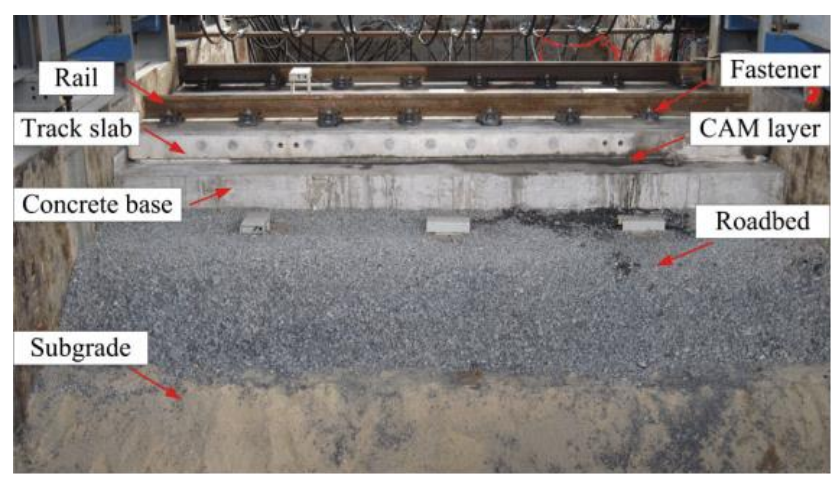

(b)

Fig. 3. Full-scale model of ballastless track in Zhejiang University

The track structure (also called the superstructure) mainly consisted of a concrete base, a CAM layer, a track slab, fasteners, and rails. The concrete base, with dimensions of $5 \mathrm{~m} \times 3 \mathrm{~m} \times 0.3 \mathrm{~m}$ and the precast track slab of the China Railway Track System I (CRTS I) with dimensions of $4.962 \mathrm{~m}$ $\times 2.4 \mathrm{~m} \times 0.19 \mathrm{~m}$ were used in the experiment. The CHN60-type rails were connected to the track slab by WJ-7 fasteners with static stiffness of $2.85 \times 10^{7} \mathrm{~N} / \mathrm{m}$. The physical parameters in Table 1 come from reference [22]. The properties of the three layers of the substructure, the ground, subgrade, and roadbed are listed in Table 1. In the following, the $2.5 \mathrm{D}$ modelling of ballasteless track are based on these material parameters. In the model, the ground size is $100 \mathrm{~m} \times 50 \mathrm{~m}$, the largest element size in the core area $(40 \mathrm{~m} \times 30 \mathrm{~m})$ is $0.5 \mathrm{~m} \times 0.5 \mathrm{~m}$, the largest size is $1 \mathrm{~m} \times 1 \mathrm{~m}$ in the far field.

Table 1. Parameters of the embankment and ground for the 2.5D FEM model

\begin{tabular}{lllllll}
\hline Layer & $\begin{array}{l}\text { Depth } \\
(\mathrm{m})\end{array}$ & $\begin{array}{l}\text { Density } \\
\left(\mathrm{kg} / \mathrm{m}^{3}\right)\end{array}$ & $\begin{array}{l}\text { S-wave } \\
\text { speed } \\
(\mathrm{m} / \mathrm{s})\end{array}$ & $\begin{array}{l}\text { Rayleigh } \\
\text { wave speed } \\
(\mathrm{m} / \mathrm{s})\end{array}$ & $\begin{array}{l}\text { Loss } \\
\text { factor }\end{array}$ & $\begin{array}{l}\text { Poisson's } \\
\text { ratio }\end{array}$ \\
\hline Roadbed & 0.4 & 2,100 & 270.0 & 253 & 0.05 & 0.30 \\
Subgrade & 2.3 & 2,100 & 180.0 & 170 & 0.05 & 0.30 \\
Ground soil & 30.0 & 2,000 & 108.0 & 101 & 0.05 & 0.42 \\
\hline
\end{tabular}




\section{Validation of 2.5D modelling of physical model}

To validate the $2.5 \mathrm{D}$ modelling of ballastless track, the model test results of vibration velocity at the roadbed surface are compared with measurement results from the physical model. The loading represents an 8 vehicles $\mathrm{CRH} 2$-type high-speed train with axle load of $140 \mathrm{kN}$, and its travelling speed was varied from 36 to $360 \mathrm{~km} / \mathrm{h}$ (10 to $100 \mathrm{~m} / \mathrm{s})$. The moving train load is applied on the physical model by the sequential loading method, which is expected to apply loads directly at positions of fasteners on a track slab with a certain phase lag to simulate the running of train wheels along the continuous rails[23].

Fig. 4 shows the validation of the calculated peak vibration velocity with the measured data (at the surface of the roadbed). For all simulated train speeds, it is clearly shown that the 2.5D FE predictions agree reasonably well with the test results. The overall agreement between the numerical and measured deflections confirms that the 2.5D FE modelling process adopted in this study is reliable and can be used with confidence to predict the railway track behaviour, for both the quasi-static and dynamic loading conditions.

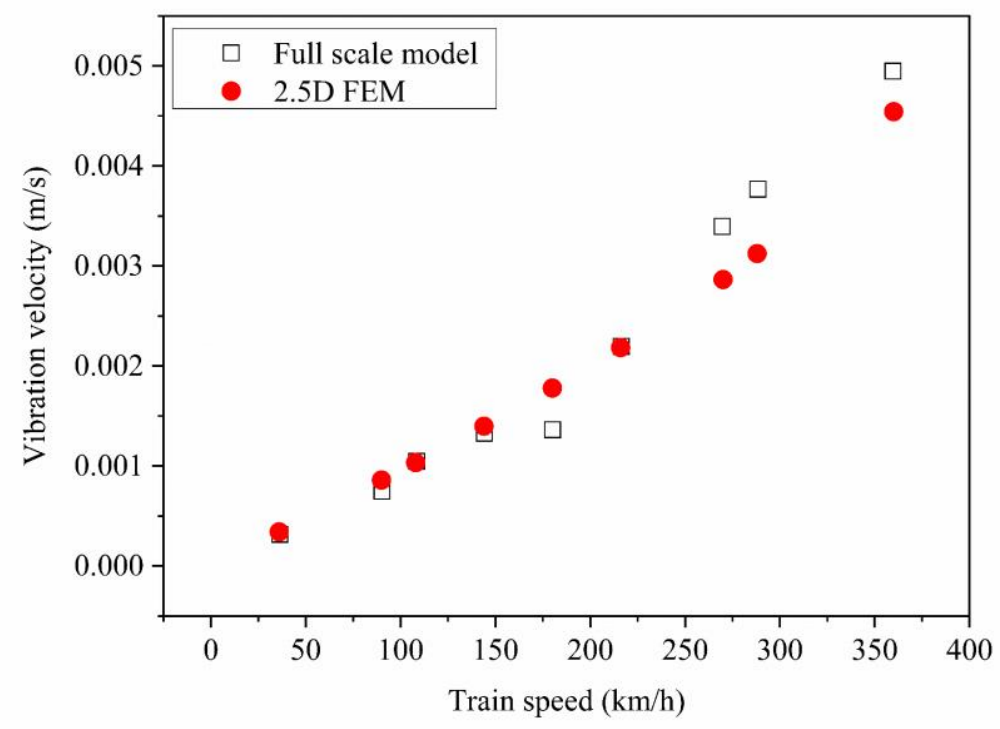

Fig. 4. Development of vibration velocity at roadbed surface with train speed

\section{Numerical results and discussion}

In Fig. 4, the highest test train speed is $360 \mathrm{~km} / \mathrm{h}$, which is close to the Rayleigh wave velocity of the underlying soil. However, from these results it is not possible to tell what is the critical speed. In this section, the same 2.5D FEM ballastless track model will be used to find the critical speed of 
the ballastless track and to predict the dynamic response under higher speeds that could not be measured in the model test due to instrument limitations.

\section{Critical speed of ballastless track system}

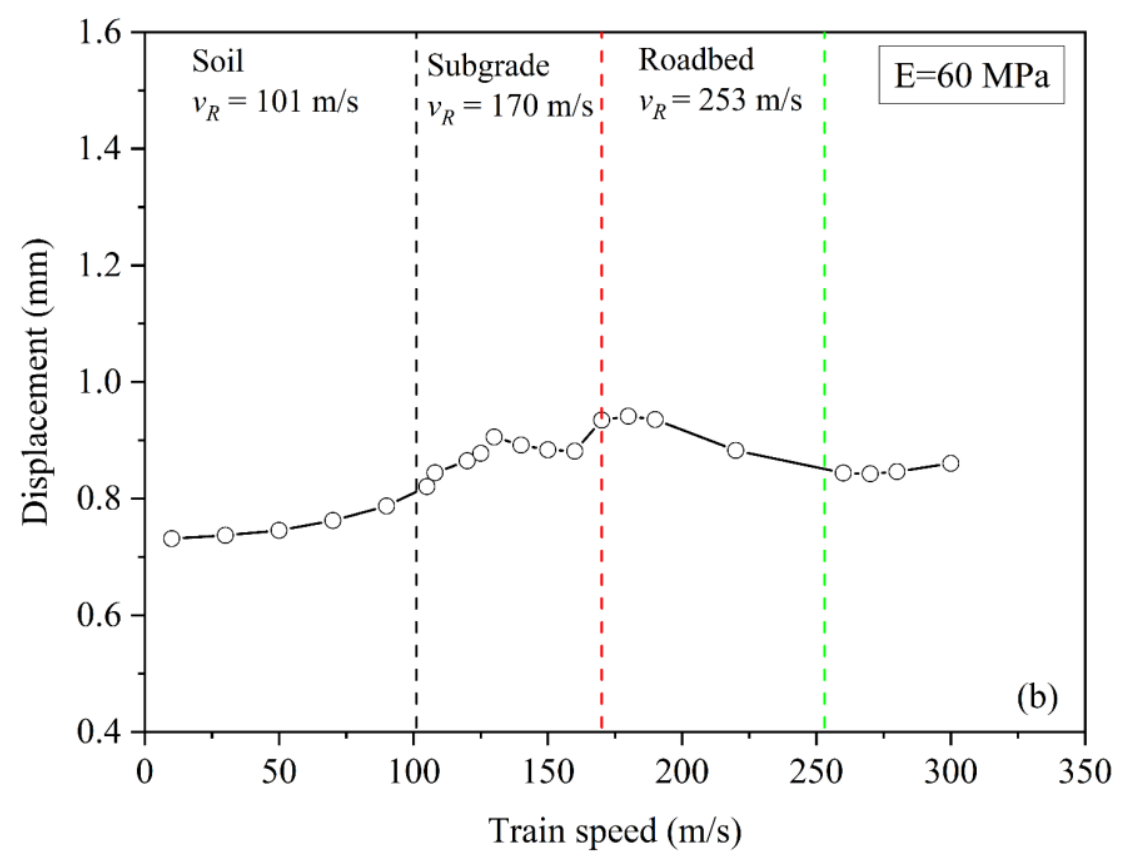

Fig. 5. Vertical displacement response of roadbed surface under varied speeds. Rayleigh wave speeds of different layers are indicated

Fig.5 presents the relationship between roadbed surface vertical displacement amplitude and train speed. It shows that the amplitude of displacement response increases slowly at first from the static value of $0.731 \mathrm{~mm}$ as the speed is increased. However, the response increases sharply once the train moves at speeds approaching the Rayleigh wave velocity of the ground soil $(101 \mathrm{~m} / \mathrm{s})$. The amplitude climbs to a peak value of $0.906 \mathrm{~mm}$ at $130 \mathrm{~m} / \mathrm{s}$ after the train speed exceeds the Rayleigh wave velocity of the ground soil, and then decreases slightly. For further increases of the train speed, the displacement grows again and reaches another peak value of $0.942 \mathrm{~mm}$ at a train speed of $180 \mathrm{~m} / \mathrm{s}$. This speed is higher than the Rayleigh wave velocity of the subgrade. These phenomena illustrate that the presence of the subgrade, roadbed and concrete base leads to a significant increase in the critical speed of ballastless track. Since the critical speed is quite close to the Rayleigh wave velocity of the subgrade, it can be concluded that the presence of the subgrade is decisive. 


\section{Investigation into critical speed of ballastless track system}

To further study the role of the subgrade in the whole ballastless track system, some parameter studies were conducted in this section.

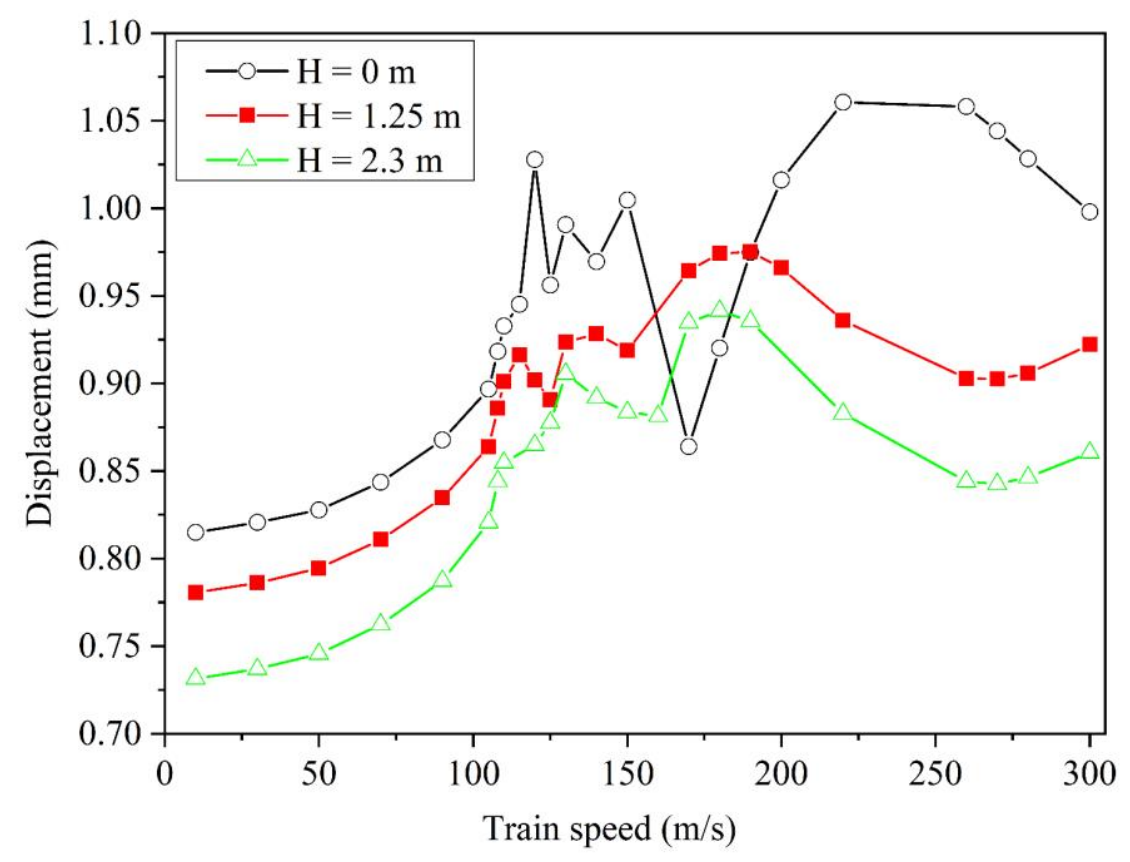

Fig. 6. Roadbed surface vertical displacement response versus train speeds at different subgrade thickness

Fig.6 illustrates the difference in the development of displacement versus train speed with various values of the subgrade thickness $H$. First, comparing the results for the ballastless track with subgrade thickness $1.25 \mathrm{~m}$ and $2.3 \mathrm{~m}$, the critical speeds are the same at $180 \mathrm{~m} / \mathrm{s}$. This indicates that the thickhness of the subgrade has no influence on the critical speed. However, with the thinner subgrade, the displacement amplitude becomes larger. For a ballastless track without subgrade, the displacement amplitudes become larger than those with the subgrade. A sharp peak occurs at $120 \mathrm{~m} / \mathrm{s}$, just above the Rayleigh wave velocity of the ground soil, and then a further peak occurs at around the Rayleigh wave speed of the roadbed $(253 \mathrm{~m} / \mathrm{s})$. It is also worth pointing out that, for all these three situations, when the train speed exceeds the Rayleigh wave velocity of the ground soil, there is always a rapid increase of the displacement amplitude.

Fig.7 shows results for three different values of Young's modulus of the ground soil. 

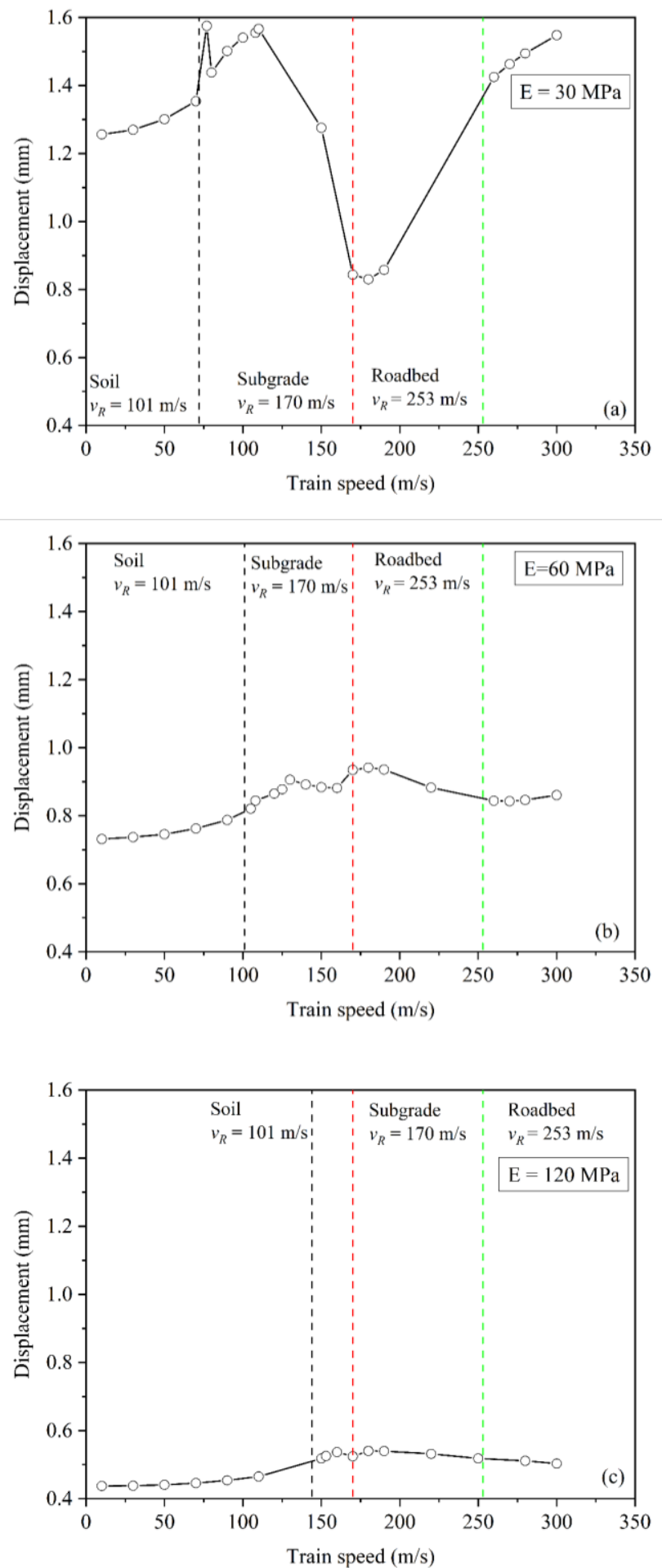

Fig. 7. Vertical displacement response versus train speeds at different soil stiffness

It can be seen that the ground soil stiffness has large effect on the displacement amplitude even at low speed. Compared with the changes of amplitude induced by the subgrade thickness in Fig. 
6, the effect of ground soil stiffness is much greater. Fig. 7 also reveals that for a sufficiently soft ground soil, the critical speed can be quite low even with the same stiffness substructure; for the softer soil with Rayleigh wave velocity $72 \mathrm{~m} / \mathrm{s}$, the critical speed reduces to $77 \mathrm{~m} / \mathrm{s}$. It means the stiff substructure can only increase the critical speed if the underlying soil is not too soft.

\section{Dynamic response of different speeds}

In this section, the dynamic stress and vibration of ballastless track are presented at three typical speeds: a low speed $(30 \mathrm{~m} / \mathrm{s})$, a sub-critical speed $(130 \mathrm{~m} / \mathrm{s})$ and the critical speed $(180 \mathrm{~m} / \mathrm{s})$.
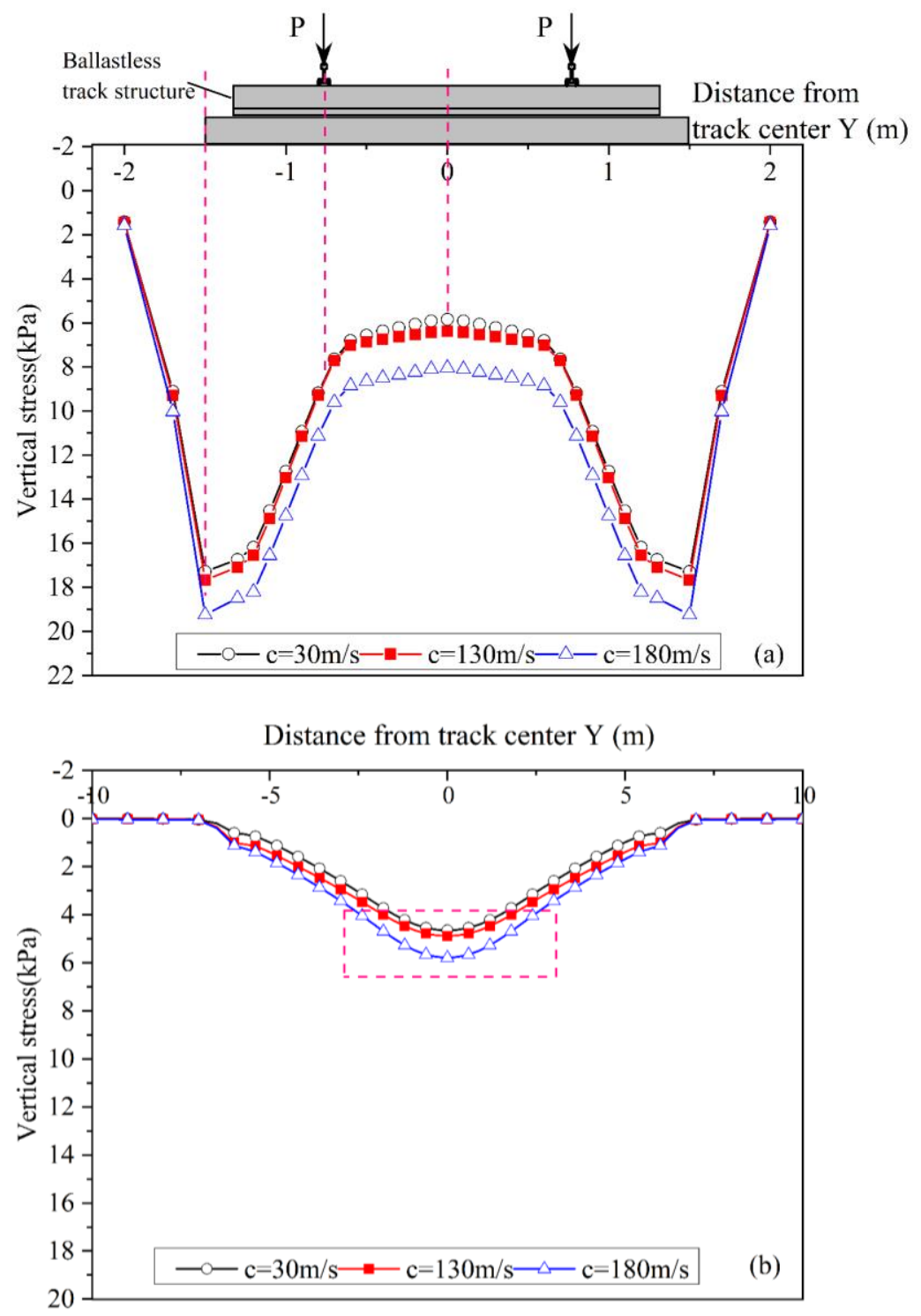

Fig. 8. Distribution of maximum vertical dynamic stress along the cross section surface: (a) subgrade surface; (b) ground surface 
Fig. 8 illustrates the lateral distribution of vertical stress at the roadbed surface and the ground surface. The lateral stress distribution looks like a saddle distribution at the roadbed surface (Fig. 8(a)) and an even distribution at the ground surface (Fig. 8(b)). For the roadbed surface, the maximum dynamic stress was found at the edge of the concrete base, this is about $20 \mathrm{kPa}$ for a train speed of $180 \mathrm{~m} / \mathrm{s}$. Between the two rails, due to the presence of the track slab the stress distribution is relatively homogeneous; it has a value of just under $50 \%$ of the maximum value. At the ground surface, the maximum value is about $5.7 \mathrm{kPa}$ at a train speed of $180 \mathrm{~m} / \mathrm{s}$. The embankment, which contains roadbed and subgrade, plays an essential role in reducing the inhomogeneity of the lateral stress distribution and the amplitude of vertical stress. However, due to the high dynamic stress at the edge of the concrete base, the requirements for the strength of the underlying roadbed layer are much greater.

Fig. 9 shows the time-history curves of the dynamic vertical stress at different depths directly beneath the track center for train speeds of $30 \mathrm{~m} / \mathrm{s}$ and $180 \mathrm{~m} / \mathrm{s}$, respectively. The max value is $8.04 \mathrm{kPa}$ for roadbed surface and $5.3 \mathrm{kPa}$ for ground surface. The amplitude of vertical stress increase $37 \%$ and $70 \%$ for roadbed and ground surface, respectively, when the train speed increases from $30 \mathrm{~m} / \mathrm{s}$ to $180 \mathrm{~m} / \mathrm{s}$. 

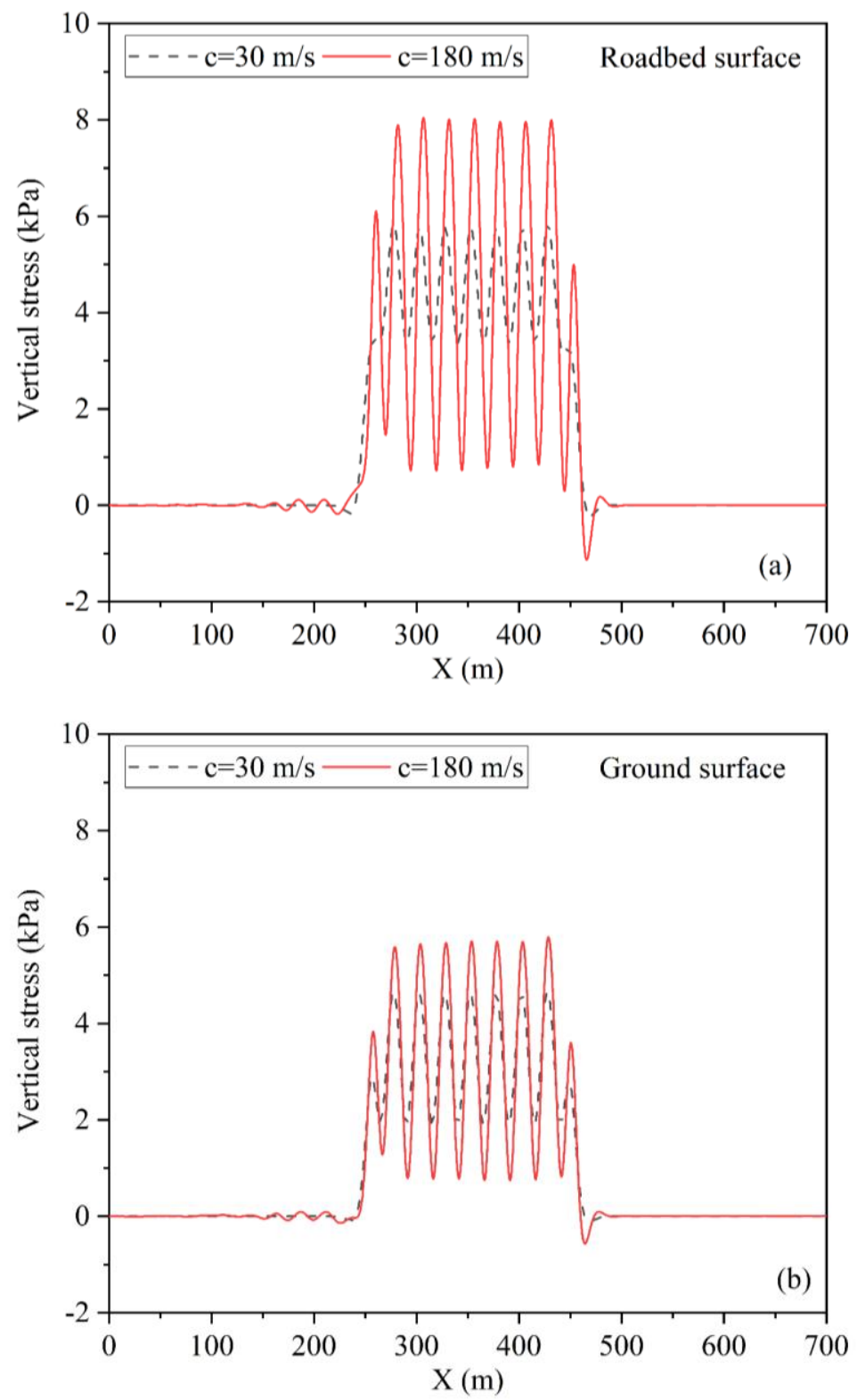

Fig. 9. The time-history curve of dynamic stress at different depths

The attenuation of maximum dynamic stress inside the embankment on the track centerline is shown in Fig. 10. It can be found that inside the roadbed layer the dynamic stress decreases very slowly at first, and then the attenuation rate increases in the subgrade layer; the dynamic stress caused by train passage eventually decays to about $60 \%$ of the initial value at the ground surface. 


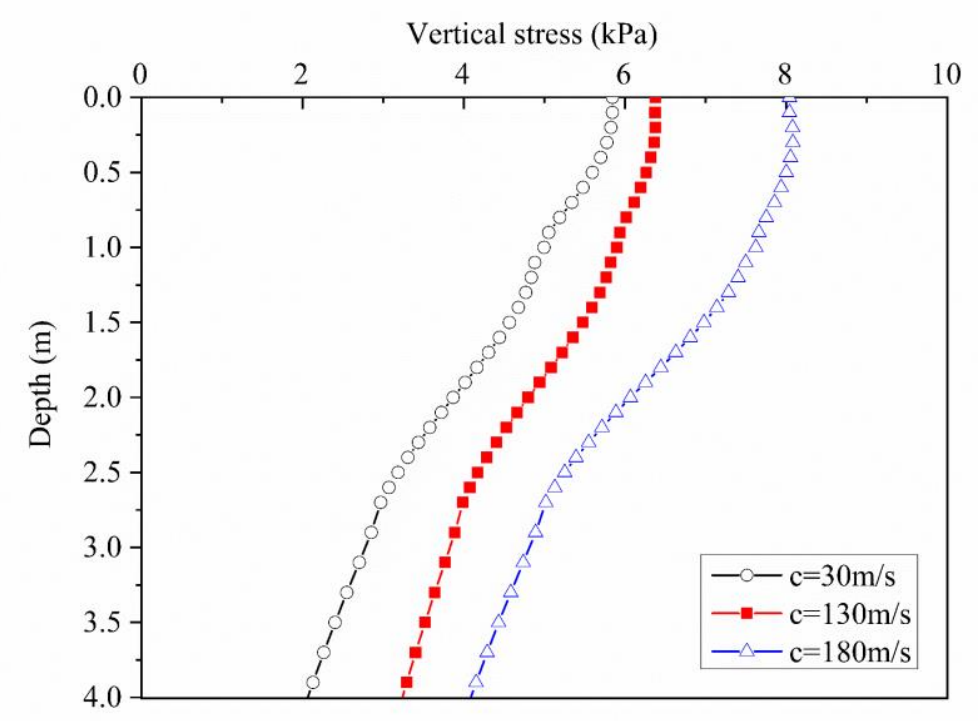

Fig. 10. Attenuation of maximum dynamic stress within ballastless track embankment on track centerline at different train speeds

In Fig. 11, the vibrations of the roadbed from a train load moving at a speed of $30 \mathrm{~m} / \mathrm{s}$ can be regarded as similar to the quasi-static deformation induced by the total weight of the whole train geometry; no significant wave propagation phenomena occur. The excitation of wave propagation phenomena becomes more obvious for a train running at a higher speed $(130 \mathrm{~m} / \mathrm{s})$ and is greater at a speed of $180 \mathrm{~m} / \mathrm{s}$. 

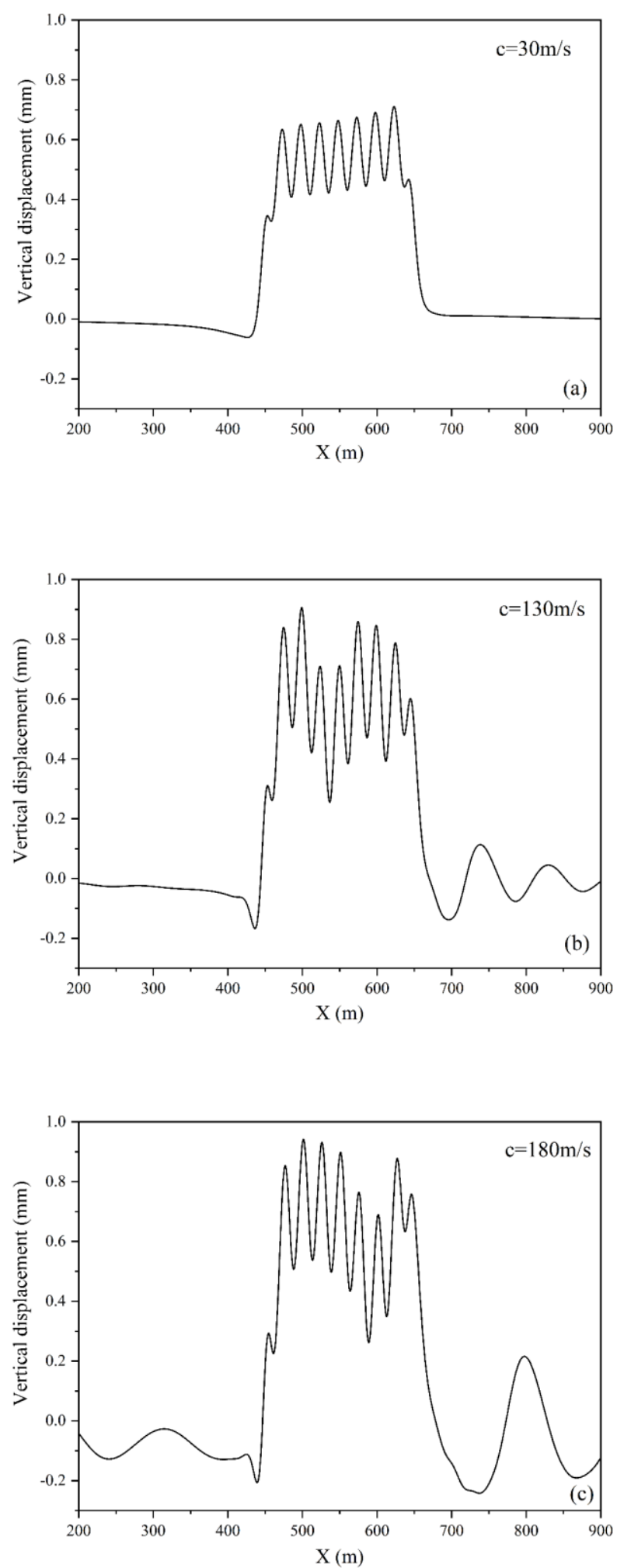

Fig. 11. Time-history curves of displacement response at roadbed surface 


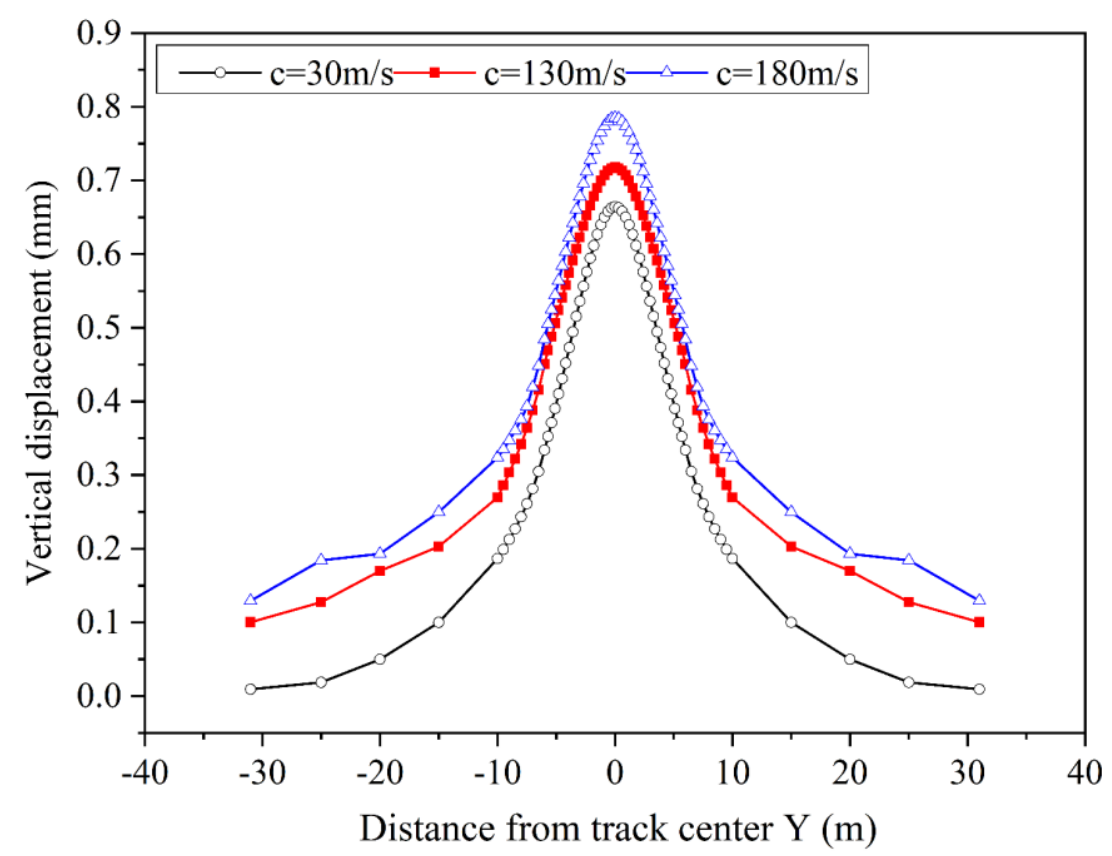

Fig. 12. Variation in vertical displacement with distance from track center

Fig. 12 presents the vertical displacement at the ground surface as a function of distance from the track center for the same three speeds. With increasing distance from the track center, all the displacement curves show an attenuating trend. At $30 \mathrm{~m} / \mathrm{s}$ the reduction in amplitude is more rapid than at the other speeds. For these higher speeds, the displacement amplitude decreases more slowly beyond $10 \mathrm{~m}$. The displacements at $180 \mathrm{~m} / \mathrm{s}$ are higher than those at $130 \mathrm{~m} / \mathrm{s}$ for all distances.

\section{Conclusions}

In this paper, a 2.5D finite element model was used to simulate the dynamic response of ballastless track subjected to train moving loads, with special reference to the critical speed. The specific modelling methodology successfully predicted the measurements taken from a full scale physical model. The obtained results confirmed that the FE modelling is trustworthy and can be used with confidence to simulate the behaviour of railway track foundations, for both the quasi-static and dynamic loading conditions. The following conclusions are drawn from the current study:

1. In general, the magnitude of the critical speed is found to be higher than the Rayleigh wave velocity of underlying soil and close to the Rayleigh wave velocity of the subgrade. 
2. The subgrade thickness is found to have no influence on the critical speed of the train-trackground system but does affect the magnitude of track displacements.

3. The stiffness of the underlying soil has a large effect on the amplitude of vibration.

4. The presence of the embankment not only improves the critical speed of the system but also plays an essential role in reducing the inhomogeneity of the transverse distribution and the amplitude of the vertical stress at the ground surface.

\section{Acknowledgements}

Financial supports from the National Natural Science Foundation of China (Grant No.51678524), Advanced Newton Fellowship of Royal Society, UK(NA140060) and Distinguished Young Scientist Program of Zhejiang Province(LR16E080002) are gratefully acknowledged.

\section{References}

[1] Priest, J. and W. Powrie, Determination of dynamic track modulus from measurement of track velocity during train passage. J Geotech Geoenviron, 2009. 135(11): p. 1732-1740.

[2] Zhai, W., Z. He, and X. Song, Prediction of high-speed train induced ground vibration based on train-track-ground system model. Earthq Eng Eng Vib 2010. 9(4): p. 545-554.

[3] Kaynia, A.M., C. Madshus, and P. Zackrisson, Ground vibration from high-speed trains: prediction and countermeasure. J Geotech Geoenviron, 2000. 126(6): p. 531-537.

[4] Madshus, C. and A. Kaynia. Dynamic ground interaction; a critical issue for high speed train lines on soft soil. Geotech Eng Transp Infrastruct. 1999. Taylor \& Francis US.

[5] Lane, H., S. Berg, and M. Larsson, Finite element calculations of rail vibration countermeasures. Vehicle Syst Dyn, 2007. 45(6): p. 565-581.

[6] Auersch, L., The effect of critically moving loads on the vibrations of soft soils and isolated railway tracks. J Sound Vib, 2008. 310(3): p. 587-607.

[7] Bian, X. and Y. Chen, An explicit time domain solution for ground stratum response to harmonic moving load. Acta Mech Sin, 2006. 22(5): p. 469-478.

[8] Bian, X., et al., Numerical analysis of soil vibrations due to trains moving at critical speed. Acta Geotech, 2016. 11(2): p. 281-294.

[9] Costa, P.A., et al., Critical speed of railway tracks. Detailed and simplified approaches. Transp Geotech, 2015. 2: p. 30-46.

[10] Grundmann, H., M. Lieb, and E. Trommer, The response of a layered half-space to traffic loads moving along its surface. Arch. Appl. Mech., 1999. 69(1): p. 55-67.

[11] Sheng, X., C. Jones, and D. Thompson, A theoretical study on the influence of the track on train-induced ground vibration. J Sound Vib, 2004. 272(3-5): p. 909-936.

[12] Hu, J., X. Bian, and J. Jiang, Critical velocity of high-speed train running on soft soil and induced dynamic soil response. Procedia Eng, 2016(143): p. 1034-1042. 
[13] Sayeed, M.A. and M.A. Shahin, Three-dimensional numerical modelling of ballasted railway track foundations for high-speed trains with special reference to critical speed. Transp Geotech, 2016. 6: p. $55-65$.

[14] Shih, J.-Y., D.J. Thompson, and A. Zervos, The influence of soil nonlinear properties on the track/ground vibration induced by trains running on soft ground. Transp Geotech, 2017. 11: p. 1-16.

[15] Bian, X., et al., Numerical analysis of soil vibrations due to trains moving at critical speed. Acta Geotechnica, 2014: p. 1-14.

[16] Bian, X., et al., Track and ground vibrations generated by high-speed train running on ballastless railway with excitation of vertical track irregularities. Soil Dyn Earthq Eng, 2015. 76: p. 29-43.

[17] Bian, X., et al., Full-scale model testing on a ballastless high-speed railway under simulated train moving loads. Soil Dyn Earthq Eng, 2014. 66: p. 368-384.

[18] Bian, X., Y. Chen, and T. Hu, Numerical simulation of high-speed train induced ground vibrations using 2.5 D finite element approach. Sci China Ser G, 2008. 51(6): p. 632.

[19] Costa, P.A., et al., Influence of soil non-linearity on the dynamic response of high-speed railway tracks. Soil Dyn Earthq Eng, 2010. 30(4): p. 221-235.

[20] Sheng, X., C. Jones, and D. Thompson, Prediction of ground vibration from trains using the wavenumber finite and boundary element methods. J Sound Vib, 2006. 293(3-5): p. 575-586.

[21] Yang, Y.-B. and H. Hung, Soil vibrations caused by underground moving trains. J Geotech Geoenviron, 2008. 134(11): p. 1633-1644.

[22] Jiang, H., Dynamic interaction of slab track structure-subgrade system and accumulative settlement in high-speed railways. 2014.

[23] Takemiya, H. and X. Bian, Substructure simulation of inhomogeneous track and layered ground dynamic interaction under train passage. J Eng Mech, 2005. 131(7): p. 699-711. 